\title{
O Programa de Microcrédito Rural Orientado e Acompanhado (Agroamigo) NOS TERRITÓRIOS DO RIO GRANDE DO NORTE ${ }^{1}$
}

\section{The Oriented And ACCompanied Rural Microcredit Program (Agroamigo) in THE TERRITORIES OF THE RIO GRANDE DO NORTE STATE, BRAZIL}

\author{
Amélio Arcangelo Pilon ${ }^{2}$ \\ https://orcid.org/0000-0002-3872-9492 \\ Emanoel Márcio Nunes ${ }^{3}$ \\ https://orcid.org/0000-0002-9045-887X
}

Submetido: 22/06/2021 / Aceito: 12/08/2021 / Publicado: 20/09/2020.

\section{Resumo}

O objetivo é analisar a importância da dinâmica do Programa de Microcrédito Rural Orientado (AGROAMIGO) no Rio Grande do Norte, por meio da sua evolução em termos de valores e distribuição por atividade econômica. Como metodologia foi utilizado o método econométrico de gráficos de dispersão e seus mapas, a partir das operações realizadas no período de dez anos do AGROAMIGO, de 2005 a 2014, com informações do Banco de Dados fornecido pelo Escritório Técnico de Estudos Econômicos do Nordeste (ETENE). Como resultado da pesquisa, percebe-se que os municípios situados nos territórios do Seridó e do Sertão do Apodi aderiam melhor ao programa. O estudo apontou ainda, que cadeias produtivas tradicionais, a exemplo da pecuária, são as com maior número de operações, e que nos municípios onde existe a menor concentração de terras, a exemplo do território Alto Oeste Potiguar, o AGROAMIGO apresentou não somente maior número de operações como também números crescentes das operações.

Palavras-chave: Agroamigo. Agricultura familiar. Microcrédito Rural. Território.

\begin{abstract}
The objective is to analyze the importance of the dynamics of the Oriented Rural Microcredit Program (AGROAMIGO) in Rio Grande do Norte, through its evolution in terms of values and distribution by economic activity. As a methodology, the econometric method of scattering graphs and their maps was used, based on operations carried out in the ten-year period of AGROAMIGO, from 2005 to 2014, with information from the extensive Database provided by the Technical Office of Economic Studies of the Northeast (ETENE). As results, the research showed the municipalities located in the territories of Seridó and Sertão do Apodi with better results to the program. Showed yet that, traditional production chains (such as livestock) are the ones with the highest number of operations of AGROAMIGO, and that in municipalities with the lower concentration of land, as in the Alto Oeste Potiguar territory,

\footnotetext{
${ }^{1}$ Este trabalho faz parte de um conjunto de pesquisas desenvolvidas no âmbito da agricultura familiar, e contou com auxílio do MDA/SDT/CNPq, através da Chamada Encomendas COSAE MDA 2013 (APQ).

${ }^{2}$ Licenciatura Plena em Matemática pela Universidade Federal do Espírito Santo (2007), Mestre em Economia pela Universidade Federal do Rio Grande do Norte (2017).

${ }^{3}$ Economista pela Universidade Federal do Rio Grande do Norte (1996), Mestre em Economia pela Universidade Federal de Uberlândia (2003), e Doutor em Desenvolvimento Rural pela Universidade Federal do Rio Grande do Sul (2009), com estágio doutoral realizado junto ao Rural Development Group da Wageningen University and Research Center, na Holanda (2008-2009).
} 
the program not only presented a greater number of operations but also increasing numbers of operations.

Key words: Agroamigo. Family Farming. Rural Microfinance. Territory.

\section{INTRODUÇÃO}

Um dos grandes desafios para estudiosos, elaboradores de políticas, lideranças políticas e pesquisadores está no direcionamento e implantação de mecanismos de política com condições de fazer surgir uma economia mais inclusiva com a capacidade de gerar mais oportunidades, melhoria das condições de vida e reduzir desigualdades. Cabe ressaltar que quanto mais desigual se apresenta um país ou região, menor será a capacidade que o crescimento econômico tem de se traduzir em transformações estruturais que sinalizem para a criação de oportunidades em um contexto de dinâmica econômica mais densa capaz de incluir cada vez mais pessoas e reduzir as desigualdades. Acontece que as oportunidades que surgem devido ao crescimento econômico tendem a ser melhor apropriadas no processo de inclusão pelos que se encontram mais preparados e qualificados para traduzir crescimento em dinâmicas internas de desenvolvimento. Geralmente, os países e regiões que conseguem melhor aproveitar os mecanismos de política são os mais preparados em termos de infraestrutura de produção e de organização coletiva, especialmente cooperativas.

A região Nordeste do Brasil ainda apresenta características significativas de um contexto de desigualdades, especialmente no meio rural. A dinâmica da sua agricultura familiar insiste na reprodução de atividades econômicas tradicionais frágeis, baseadas em estruturas precárias e com ausência e deficiência das organizações coletivas. E esse é um contexto da região Nordeste que os seus atores principais, os agricultores familiares e suas organizações coletivas, necessitam estar mais preparados e qualificados para que as ações e os mecanismos de política sejam cada vez mais efetivos no sentido da diversificação da agricultura familiar e dinamização das economias regionais. Existe uma necessidade presente e urgente de capacidades no sentido de possibilitar a melhoria e continuidade dos serviços de assistência técnica e extensão rural (ATER), de melhor organização coletiva, da agregação de valor através da integração da agricultura familiar à agroindústria de pequeno porte, da construção de mercados e acesso a canais de comercialização e do acesso e uso cada vez mais qualificado do crédito.

E foi no sentido de qualificar a utilização do crédito e contornar problemas na operacionalização do PRONAF B, modalidade do Programa Nacional de Fortalecimento da Agricultura Familiar (PRONAF) mais acessada na região Nordeste, que o Banco do Nordeste (BNB) lançou no ano de 2005 o Programa de Microcrédito Rural Orientado (AGROAMIGO). O AGROAMIGO consiste em uma estratégia de microfinança rural que possui a coordenação do Banco do Nordeste, com a execução realizada em parceria com o Instituto Nordeste Cidadania (INEC). É uma estratégia considerada uma iniciativa pioneira, no que diz respeito à oferta de microcrédito no Brasil, e tem como finalidade apoiar atividades econômicas baseadas na agricultura familiar por meio da concessão de financiamento para agricultores familiares e suas organizações coletivas.

Diante do exposto, o presente artigo pretende responder a seguinte questão: como se deu a evolução da operacionalização do Programa AGROAMIGO no período compreendido entre 2005 a 2014; e quais as principais atividades apoiadas e os pontos de concentração do acesso e distribuição por parte dos agricultores familiares? Como hipótese, defende-se que a maior parte dos recursos tem sido direcionada de forma predominante para cadeias 
produtivas tradicionais, especialmente para a pecuária, e as operações concentradas em determinados pontos do Rio Grande do Norte. Esse caráter desigual torna cada vez necessária tanto a ampliação dos recursos do AGROAMIGO para cadeias produtivas novas, visando a diversificação da agricultura familiar, como uma melhor descentralização das operações no estado.

Neste sentido, o objetivo deste artigo é analisar a dinâmica do Programa AGROAMIGO, por meio da distribuição dos recursos sua evolução em termos de valores e de atividades econômicas, considerando a concentração de liberações do programa por município e nos territórios do no Rio Grande do Norte, ano a ano, nos primeiros dez anos de operacionalização do programa, ou seja, de 2005 a 2014.

Assim, na primeira seção são apresentados dados gerais do AGROAMIGO, como e porque ele surgiu, relacionando o crédito ao desenvolvimento. $\mathrm{Na}$ seção 2 são apresentados os territórios rurais e da cidadania do Rio Grande do Norte, para melhor situar o leitor na análise realizada com os dados na seção 4. A seção 3 apresenta a metodologia utilizada para a análise dos dados, através do método de Econometria Espacial, escolhido por ser adequado para a análise regional. Na seção 4 foi realizada a análise dos dados, mostrando gráficos usuais, de Dispersão e mapas, como forma de mostrar a distribuição dos contratos nos territórios do estado do Rio Grande do Norte nos primeiros dez anos do AGROAMIGO. E na seção 5 estão as considerações finais.

\section{FUNDAMENTAÇÃO TEÓRICA}

\section{O Crédito e o Microcrédito: políticas de viés financeiro e de desenvolvimento}

De acordo com fundamentos da teoria econômica, todo investimento viável deve ser realizado, e se o empreendedor não estiver com o dinheiro suficiente para a estruturação do empreendimento o crédito deve ser ofertado na quantidade adequada. Assim, regiões com grau similar de desenvolvimento teriam grau similar de continuidade deste desenvolvimento. Entretanto, devido a informações assimétricas e outras restrições, os emprestadores nem sempre têm a certeza da assertividade do empreendimento, às vezes causando o que se denomina exclusão financeira pela indisponibilidade, ou negativa, do crédito. Crocco et al. (2013) classificam dois tipos de exclusão financeira: a exclusão pela dificuldade de acesso e pela dificuldade de uso. A primeira é caracterizada pela falta da presença bancária, onde não há agência ou correspondente que preste o serviço financeiro. Já a segunda é caracterizada pela dificuldade de ser aceito no meio financeiro, de abrir uma conta, de tomar um empréstimo bancário, etc. Esta última geralmente é causada pela exclusão social ou pela falta de informação. econômico:

Schumpeter (1988) disserta como a concessão do crédito opera no sistema ... como uma ordem para o sistema econômico se acomodar aos propósitos do
empresário, como um comando sobre os bens de que necessita: significa confiar-
lhe forças produtivas. É só assim que o desenvolvimento econômico poderia surgir
a partir do mero fluxo circular em equilíbrio perfeito. E essa função constitui a
pedra angular para a moderna estrutura de crédito. (SCHUMPETER, 1988, p. 74) 
Ou seja, o crédito é a alternativa à ausência de capital financeiro preexistente ao alcance do empreendedor, no entanto, a falta da oferta ou a dificuldade de tomar crédito é prejudicial ao desenvolvimento. No Brasil, conforme Nunes et al (2015a), a exclusão financeira geralmente causa dificuldades ao desenvolvimento, pois o crédito é inibido não só pelo seu custo com taxas extremamente elevadas se comparadas a outros países, mas também pela assimetria de informação e insuficiência de garantias. Freitas (2013) observa que a sofisticação do setor bancário brasileiro, não se traduz em termos de ampliação e diversificação do alcance dos serviços financeiros e da eficiência social das organizações.

Na região Nordeste a exclusão pela dificuldade de acesso parece ser maior que nas regiões mais desenvolvidas do país, já que a razão entre quantidade de cidades com agência bancária e o total de cidades da região é menor que em todo nacional $-51 \%$ das cidades nordestinas tem ao menos uma agencia bancária, enquanto no Brasil esse índice é de $65 \%$, conforme tabela 1 a seguir. A dificuldade de uso também está presente na região, pois a menor capilaridade dos bancos faz com que os poucos presentes escolham seus clientes por vários motivos.

\begin{tabular}{|c|c|c|c|}
\hline & Total de Cidades & Cidades com Agência & $\begin{array}{l}\text { Razão cidades com agência / } \\
\text { Total de cidades }\end{array}$ \\
\hline Brasil & 5565 & 3599 & 0,65 \\
\hline Nordeste & 1794 & 913 & 0,51 \\
\hline
\end{tabular}

Tabela 1. Relação presença de agências bancárias no Nordeste e no Brasil em dez/2014 Fonte: Febraban e IBGE, 2015. Elaboração dos autores.

Kaztman e Filgueira (1999), então membros da Comissão Econômica para a América Latina (CEPAL) em Montevidéu, Uruguai, conceituam estrutura de oportunidades como sendo possibilidades de acesso a bens e a serviços, ou a desempenho de atividades. A defesa é a de que oportunidades incidam sobre melhoria das condições de vida, conforme Nunes et al (2020), isso por permitir ou facilitar aos residentes do lugar o uso de seus próprios recursos ou porque provem novos. Na mesma obra, os autores conceituam ativos como o subconjunto dos recursos cuja mobilização permite o aproveitamento das estruturas de oportunidades existentes em determinado momento. A região Nordeste do Brasil é conhecida pelas dificuldades econômicas mais visíveis do que outras regiões do país, devido aos elevados níveis de desigualdade causados pela reprodução de velhas receitas que muitas vezes aprofundam desigualdades existentes e acabam criando novas.

Em décadas anteriores, houve tentativas de fazer com que o Nordeste apresentasse níveis de crescimento econômico condizentes, e até superiores, com as regiões Sul e Sudeste. Tais tentativas eram marcadas por defender o crescimento pela industrialização, o que não foi suficiente para a redução da desigualdade que se fortalecia e se ampliava diante do dos crescentes níveis de crescimento. A pobreza que já era maior na zona rural seria menor, pois a migração para as cidades que se industrializavam daria a tão sonhada dignidade para o migrante do meio rural, caracterizado por possuir baixos índices educacionais, não estando preparado ou qualificado para o emprego nas indústrias. Aos que ficaram no meio rural, o cotidiano de privações continuou estático com a concentração de terras ainda maior que antes e a falta de tecnologias que reduzia a capacidade de sobreviver.

Agricultores familiares da região ficaram então com poucos ativos disponíveis em suas estruturas de oportunidades para sobreviverem economicamente. $\mathrm{O}$ crédito não se 
encontrava disponível para os agricultores familiares, que se utilizavam da agricultura de autoconsumo e da venda do rebanho que não morria na seca para suprir as eventualidades. Freitas (2013) argumenta o motivo desta negativa de crédito para os menos abastados:

\begin{abstract}
Geralmente, a oferta bancária de serviços financeiros não está conectada às demandas da população de baixa renda, pelo fato de essa população desenvolver atividades produtivas diversificadas e em escala reduzida, além de possuírem pouca ou nenhuma garantia patrimonial como contrapartida para as organizações financeiras. (FREITAS, 2013).
\end{abstract}

No ano de 1996, o governo federal cria uma modalidade de crédito rural destinada aos agricultores familiares, o Programa Nacional de Fortalecimento da Agricultura Familiar (PRONAF), com disponibilização de recursos financeiros para investimento e custeio das atividades econômicas, com juros subsidiados e muito abaixo dos de mercado. A partir do início dos anos 2000, foi direcionado um montante maior para o programa, mas ainda não estava atendendo às necessidades do Nordeste, onde, conforme Nunes et al (2014) possui mais de $50 \%$ dos estabelecimentos dos agricultores familiares do país. A não simetria de informações, a ausência ou deficiência de serviços de assistência técnica, conforme Nunes et al (2018), e a necessidade de garantias reais fazia com que o PRONAF B, destinado a agricultores familiares de mais baixa renda, não fosse aproveitado por seus possíveis beneficiários. Visando resolver problemas na aplicação dos desses recursos, o Bando do Nordeste do Brasil (BNB) lançou no ano de 2005 o programa de microcrédito rural orientado, o AGROAMIGO. Nunes et al. (2015a) explica o surgimento do programa:

\begin{abstract}
Acontece que até o ano 2000 havia sérios problemas na operacionalização do crédito por meio do PRONAF B, que impactavam nos resultados e gerava crescente inadimplência devido à deficiência na orientação ao agricultor familiar e no acompanhamento dos empreendimentos, o que desviava o objetivo do PRONAF. Com a finalidade de reduzir as distorções geradas pela metodologia do PRONAF B na região Nordeste, o Banco do Nordeste do Brasil (BNB) lançou no ano de 2005 o Programa de Microcrédito Rural Orientado e Acompanhado (AGROAMIGO). (NUNES, 2015).
\end{abstract}

Já Abramovay (2012) explica que o Agroamigo objetiva ampliar e qualificar o processo de crédito para a agricultura familiar, reduzindo o custo, facilitando o acesso e orientando o crédito.

O AGROAMIGO agora tem mais de dez anos de existência, e já atendeu a mais de um milhão de agricultores familiares (1,12 milhão de clientes ativos em março de 2017), aplicou mais de $\mathrm{R} \$ 10,5$ bilhões em 3,73 milhões de operações contratadas neste período, e se tornou o maior programa de microcrédito rural da América Latina. Santos (2007) defende que o programa AGROAMIGO é necessário e não se caracteriza como paternalista:

\footnotetext{
Um outro motivo de muitas das tentativas de "provar" os efeitos positivos de programas de microcrédito tem origem na incompreensão do papel, dos potenciais, e dos limites, do microcrédito como um instrumento, entre muitos outros, de desenvolvimento econômico e social. Propagado como panacéia para suprir deficiências de políticas sociais, ou até mesmo paliativo para as consequências mais nefastas de desequilíbrios macroeconômicos, espera-se do microcrédito profundos impactos de natureza econômica e social junto aos seus clientes, denominados de forma paternalista beneficiários. Ao contrário de uma transferência de renda de um programa social, um (micro) crédito, cujo principal deve ser pago acrescentado de juros, não pode ser caracterizado como um benefício. (SANTOS, 2007)
} 
Soares (2011) explica que estudos de análise de importância de programas de microcrédito tendem a se aterem à comparação entre valor empregado e retorno financeiro, sem dar importância a fatores ditos não econômicos, a exemplo das variações sociais caracterizadas pelo acesso a bens e serviços por parte dos beneficiários. Para ele, a importância maior que se dá às análises de impacto, em detrimento às que monitoram os clientes, acabam por não verificarem a função de efetiva redução da pobreza do programa.

Abramovay (2012) finaliza o livro que pretendeu mensurar o impacto dos primeiros cinco anos do programa com a seguinte frase:

\begin{abstract}
A garantia de acesso ao crédito, provavelmente, permite que as famílias se organizem para fazer frente a suas necessidades de consumo, o que é um dos mais importantes fatores no combate à pobreza. (ABRAMOVAY, 2012, p.116).
\end{abstract}

\title{
Do microcrédito ao AGROAMIGO
}

De acordo com Santos (2007), existem relatos de empréstimos para pessoas mais pobres já por volta de 1890, na Alemanha, quando uma Associação do Pão cedia farinha a camponeses endividados. O microcrédito como empréstimo de valor monetário começa por volta de 1976, em Bangladesh, quando o professor Muhammad Yunus começa a emprestar pequenas quantias em dinheiro a famílias pobres ao redor da universidade onde lecionava. Esses empréstimos se caracterizavam pelo fato da maioria dos tomadores ser de mulheres, utilizando o sistema de garantias morais mútuas, onde um grupo de cinco pessoas se comprometia igualmente pelo pagamento do valor emprestado a cada um deles. Com forte ajuda do Banco Mundial, o projeto de Yunus cresceu e se tornou um banco especialista nessa modalidade de crédito, o Grammen Bank (Banco da Aldeia, na língua bengalesa).

$\mathrm{O}$ modelo de microcrédito original concebido por Yunus, com o intuito de combate à pobreza, inicialmente não foi muito bem aceito no Brasil, pois o microcrédito teve seu início como instrumento de financiamento para micro e pequenas empresas, em um modelo comercial. Para Santos (2007), muitos programas de microcrédito atualmente no Brasil surgiram ainda na década de 1990 e foram iniciados com grande utilização pelos bancos públicos, cooperativas de crédito e organizações não governamentais. Na região Nordeste, o maior projeto foi implantado pelo Banco do Nordeste do Brasil, como instituição financeira a analisar e conceder o crédito, iniciando-se assim o programa CREDIAMIGO em 1998. Sete anos depois, em 2005, para atender a agricultores familiares e suas organizações coletivas, deu-se início ao AGROAMIGO.

O AGROAMIGO nasce como um programa de microfinanças rural do BNB, operacionalizado em parceria com o Ministério de Desenvolvimento Agrário (MDA) e o Instituto Nordeste Cidadania (INEC), que, de acordo com Nunes et al (2015a) coordena os programas de microcrédito CREDIAMIGO e AGROAMIGO. Consiste em concessão de crédito na modalidade de microcrédito a agricultores familiares enquadrados no PRONAF B, no Nordeste e no norte dos estados de Minas Gerais e Espírito Santo. A sua principal característica é a atuação do Assessor de Microcrédito Rural ${ }^{2}$, e sua capacidade de avaliação do cliente, considerando as intenções e potencialidades, e incentivando o desenvolvimento de atividades econômicas no meio rural.

A presença do assessor (agente de crédito) classifica o AGROAMIGO como um crédito produtivo orientado, e estes agentes de crédito são os responsáveis pela visita aos agricultores familiares, pela avaliação socioeconômica e por parte da análise para a concessão do crédito. Certamente o AGROAMIGO e a sua forma de contratação (menor burocracia, 
garantia de avalista) faz parte da estrutura de oportunidades que Kaztman e Filgueira (1999) citam como necessárias para que a público possa utilizar seus ativos para sair da vulnerabilidade.

Desde seu início, o AGROAMIGO manteve crescimento tanto no número de contratos como no total de valores liberados (gráfico 3), e no valor médio das operações (gráfico 4), durante a maioria dos anos. Isso demonstra que o programa está sendo cada vez mais utilizado pelo público alvo e, em particular, o aumento no valor médio das operações tende a deixar menor a contradição entre número de contratos e valores totais em liberações do PRONAF na região Nordeste.

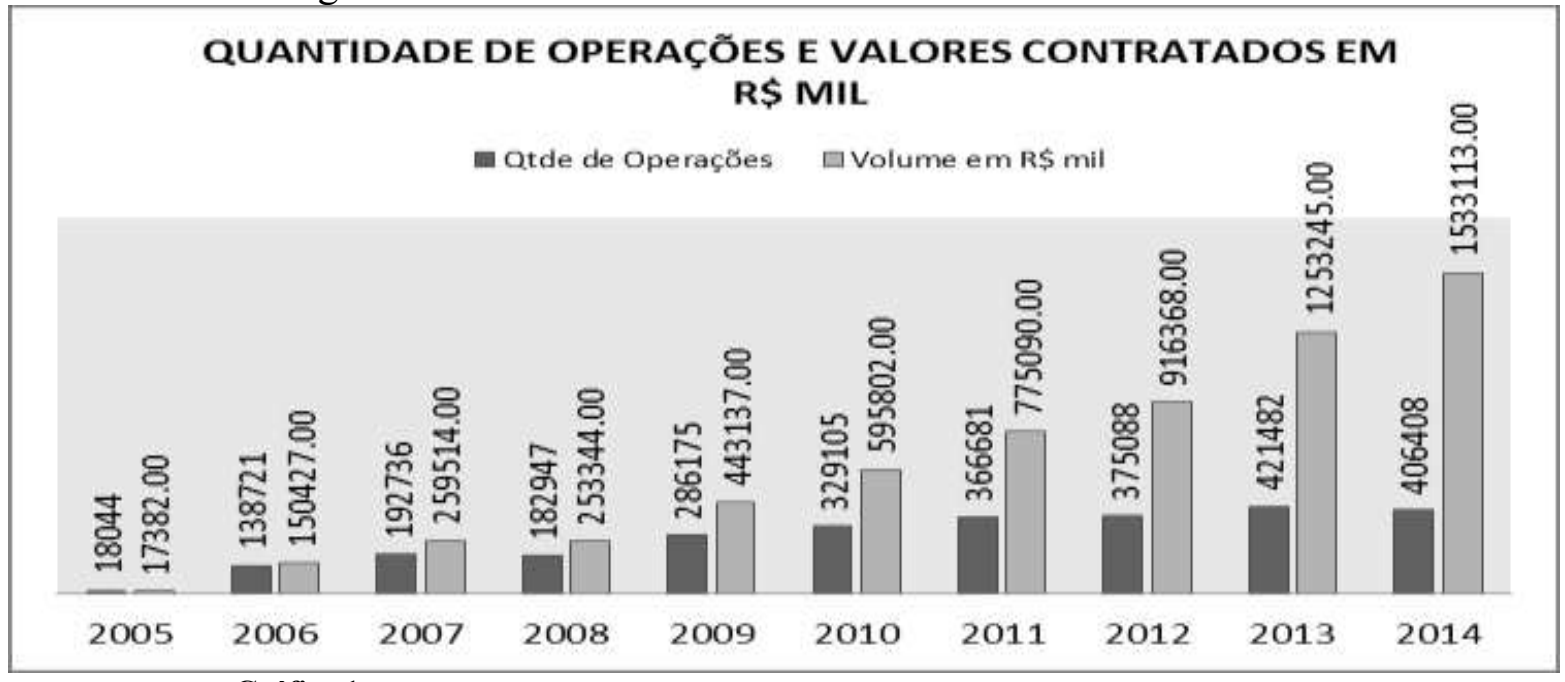

Gráfico 1. AGROAMIGO - Evolução de número de contratos e valores liberados (2005 - 2014)

Fonte: BNB, 2017.

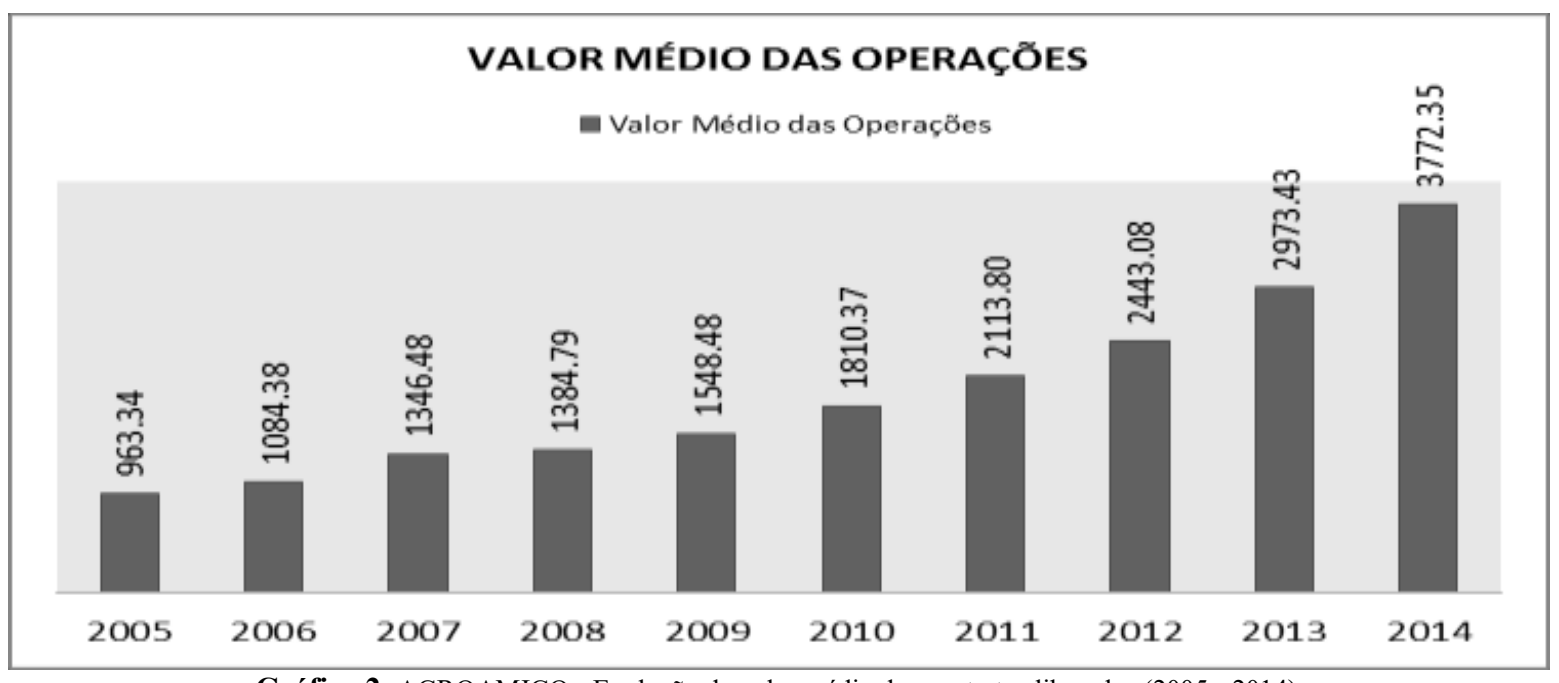

Gráfico 2. AGROAMIGO - Evolução do valor médio dos contratos liberados (2005 - 2014)

Fonte: BNB, 2017.

Quanto à participação dos tomadores por gênero, não houve muita diferença entre o público masculino e feminino (52\% e $48 \%$, respectivamente). Como não há no programa AGROAMIGO um foco nos tomadores do sexo feminino, essa participação demonstra que o programa apresenta uma relativa igualdade de gênero dentre seus tomadores.

Um problema ainda a ser enfrentado é o fato de as operações do AGROAMIGO ainda se concentrarem hegemonicamente numa cadeia produtiva tradicional, que é a cadeia da bovinocultura, um subsetor pecuária (ver gráficos 5 e 6). Este é um problema de raízes na 
cultura e nas necessidades de agricultores, que veem seu rebanho muitas vezes como uma poupança, para sobreviver a longos períodos de seca ou para aproveitar oportunidades de maior preço ou peso em algumas épocas do ano.

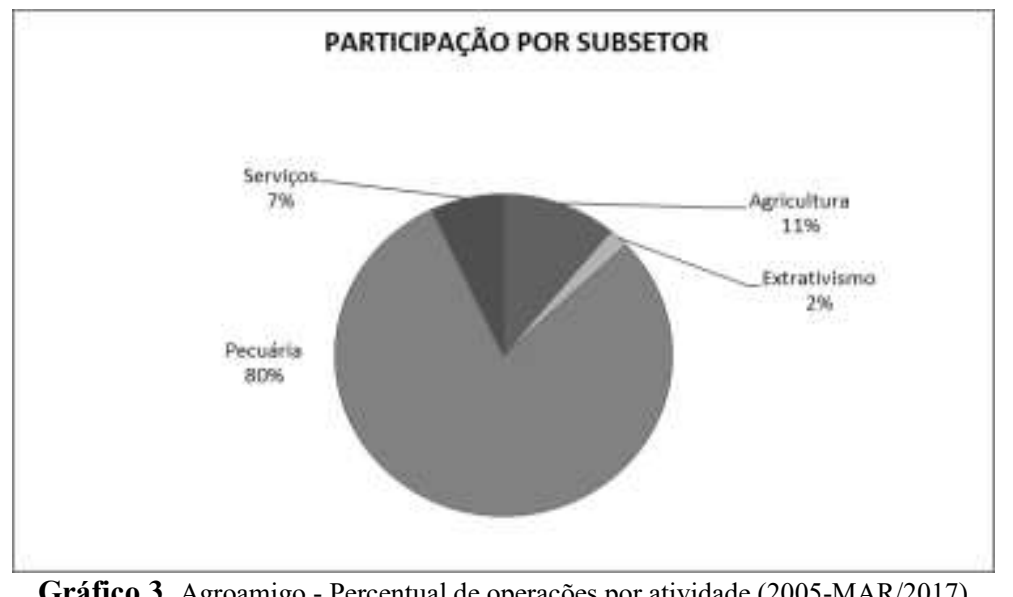

Gráfico 3. Agroamigo - Percentual de operações por atividade (2005-MAR/2017) Fonte: BNB, 2017.

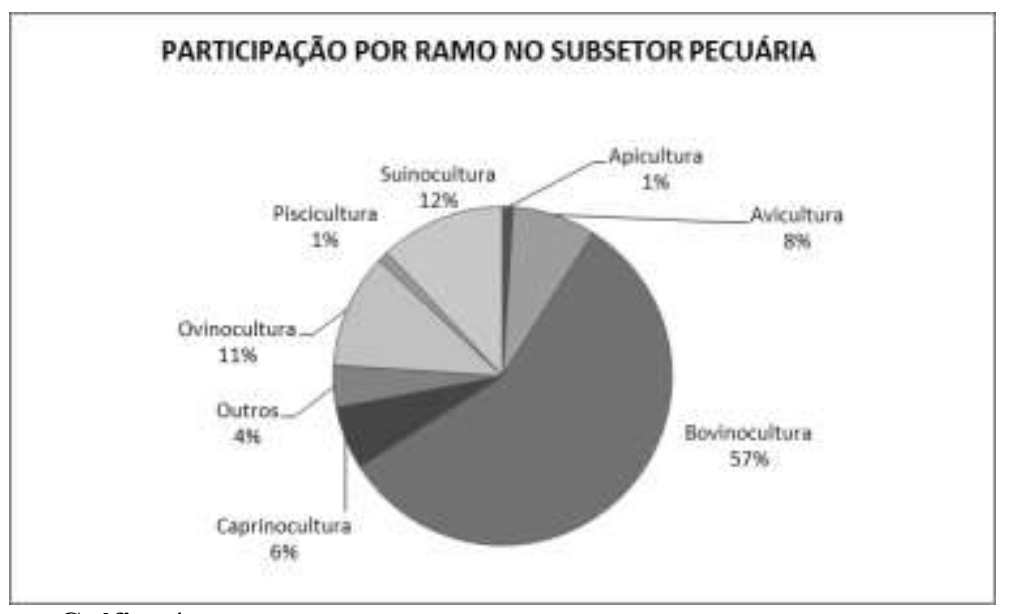

Gráfico 4. Participação do por Ramo no Subsetor Pecuária (2005-MAR/2017) Fonte: BNB, 2017.

$\mathrm{Na}$ busca de superar dificuldades enfrentadas pelos municípios, chegou-se a implementação de algo que desenvolvesse políticas públicas sob a ótica supra municipal. Sob administração do MDA e com recursos do orçamento, conforme Nunes et al (2015b), o Programa de Desenvolvimento Sustentável dos Territórios Rurais (PRONAT) foi implementado em 2003, criando uma nova institucionalidade que representaria os interesses da agricultura familiar e que fosse coordenada e articulada por um grupo de municípios na busca de objetivos comuns. Surgia o território, cuja maior diferença em relação ao Pronaf Infraestrutura e Serviços - programa anterior sob administração das prefeituras - foi a ampliação para dois terços da representação da sociedade civil nos Colegiados de Desenvolvimento Territorial (CODETERs), enquanto que no programa anterior usava-se a igualdade de representação entre sociedade civil e poder público.

De acordo com Nunes et al (2015b), no ano de 2008 foi lançado o Programa Territórios da Cidadania (PTC), com a finalidade de direcionar para alguns territórios intervenções governamentais com a ênfase no combate à pobreza e na conquista da cidadania, e contava com políticas coordenadas por 22 ministérios. O território passa a articular estratégias de execução de políticas públicas integrando os ministérios ao programa, com 
recursos já dotados no orçamento do governo federal ou do congresso - por emendas parlamentares. Leite e Júnior (2012) exaltam os colegiados como a parte mais importante da instituição território: "O espaço representado pelo colegiado como uma instância de participação, discussão e decisão, é ponto alto na ossatura institucional dos programas" (LEITE; JÚNIOR, 2012, p. 664).

Já Nunes et al. (2015b) caracterizam o Programa Nacional de Desenvolvimento Sustentável de Territórios Rurais (PROINF) como uma parte do PRONAF, a parte onde o Colegiado de cada território deve se debruçar para avaliar as melhores medidas a serem tomadas, os empreendimentos e ações que serão mais importante para o desenvolvimento do território, o que deve ser solicitado que entre no orçamento: "O PROINF é uma ação orçamentária do PRONAT, cuja finalidade é financiar projetos de desenvolvimento territorial definidos pelos Colegiados Territoriais. (NUNES et al., 2015, p. 531).

Assim um território rural ou da cidadania é uma união de municípios com a finalidade de juntos obterem maior participação no orçamento federal ou estadual destinado à agricultura familiar. Com essa união, a região onde é implantado o território se torna mais forte politicamente e as políticas desenvolvidas dentro deste território passam a ter não só o acompanhamento por parte do colegiado como esse passa a decidir sobre estas políticas. No Rio Grande do Norte foram criados 10 (dez) territórios rurais e da cidadania, abrangendo todos os municípios do estado, sem que algum município pertença a mais que um território, numa correspondência biunívoca entre os territórios e os municípios.

\section{METODOLOGIA}

A pesquisa realizada para este artigo considera o recorte territorial na análise da evolução do AGROAMIGO, recorte este definido pela Secretaria de Desenvolvimento Territorial (SDT), do Ministério do Desenvolvimento Agrário (MDA). E o estudo realizado abrange os dez territórios do Rio Grande do Norte, a seguir: Açu-Mossoró, Alto Oeste Potiguar, Sertão do Apodi, Sertão Central Cabugi e Litoral Norte, Seridó, Mato Grande, Potengi, Terra dos Potiguaras, Trairi e Agreste Litoral Sul, como mostra a figura 1.

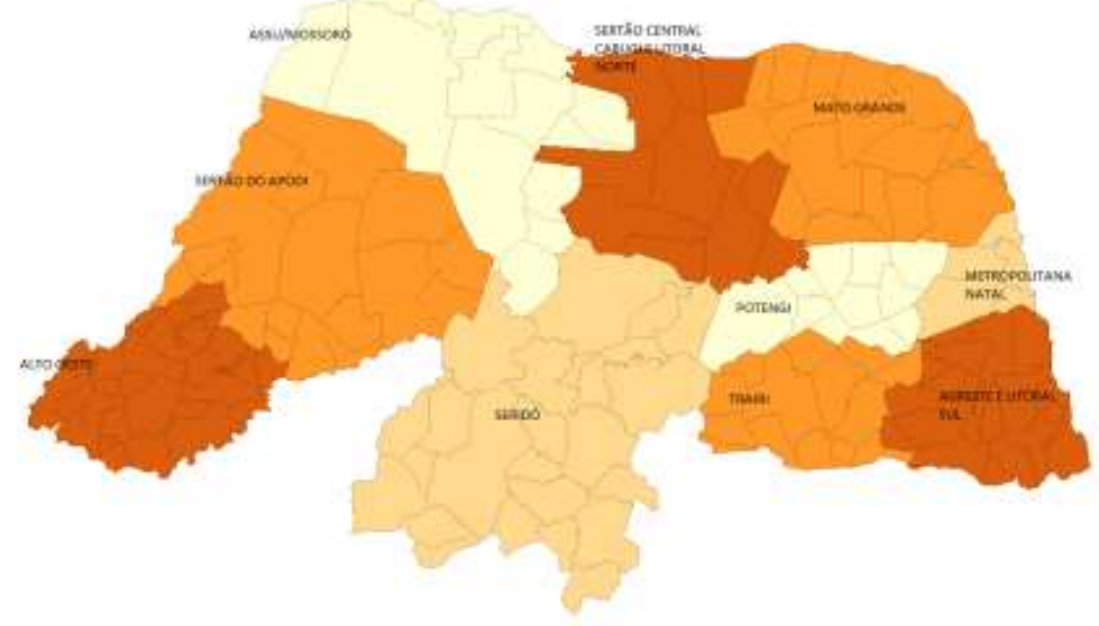

Figura 1. Mapa dos Territórios da Cidadania no Estado do RN. Fonte: MDA, 2016. 
Para esta pesquisa utilizamos, além das operações que constam como liberação de crédito entre os anos de 2005 e 2014 nos municípios do Rio Grande do Norte, as operações de prorrogação, apenas para gerar um indice de prorrogação. Classificamos cada operação por território, por município, por ano, por gênero, por ramo da atividade, etc, e utilizando os métodos citados a seguir. A escolha da Econometria Espacial se dá pela facilidade que ela proporciona na análise dos resultados graças a seus recursos gráficos. Segundo Anselin (1988), apud Silva e Jayme-jr. (2013), Econometria Espacial é definida como uma coleção de técnicas que trata das peculiaridades causadas pelo espaço na análise estatística dos modelos regionais.

\section{Diagrama de Dispersão}

Sabemos que dois pontos definem uma reta, mas se tivermos três ou mais isso passa a ser um problema que só poderá ser resolvido se todos os pontos estiverem alinhados. Para uma série maior, esta reta se tornaria verdadeiramente impossível. Utiliza-se então o grau de alinhamento dos pontos em torno de uma reta. Esse coeficiente é chamado de coeficiente de correlação linear.

Uma vez calculado o coeficiente, este terá como resultado o valor entre 1 e -1 , valor semelhante à inclinação da reta resultante de uma regressão simples entre duas variáveis. Assim poderemos medir através da regressão e visualizar através da reta num gráfico o coeficiente de correlação entre duas variáveis.

O valor do coeficiente $(r)$ e o resultado da equação:

$$
\begin{aligned}
& \text { variáveis } x \text { e } y, S_{x x}=\sum_{i=1}^{n}\left(x_{i}\right)^{2}-\frac{\left(\sum_{i=1}^{n} x_{i}\right)^{2}}{n} S_{x x}=\sum_{i=1}^{n}\left(x_{i}\right)^{2}-\frac{\left(\sum_{i=1}^{n} x_{i}\right)^{2}}{n} \\
& \mathrm{e}^{S_{y y}=\sum_{i=1}^{n}\left(y_{i}\right)^{2}-\frac{\left(\sum_{i=1}^{n} y_{i}\right)^{2}}{n} S_{y y}=\sum_{i=1}^{n}\left(y_{i}\right)^{2}-\frac{\left(\sum_{i=1}^{n} y_{i}\right)^{2}}{n}} \text { é a variância de } x,
\end{aligned}
$$

Utilizamos o Gráfico de Dispersão neste trabalho para analisarmos a correlação entre o número de operações do programa AGROAMIGO e de estabelecimentos agrícolas, identificando no gráfico os municípios que apresentam maior quantidade de operações e os territórios que melhor se apropriaram do programa.

\section{RESULTADOS E DISCUSSÃO:}

\section{Evolução e Números Gerais}

No estado do Rio Grande do Norte foram efetuadas 58.794 aberturas de crédito (que chamaremos de operações) do AGROAMIGO no período de 2005 a 2014. Destas, 57.458 foram com a finalidade de investimento e 1.336 de custeio. Como o número de operações de custeio representam uma parte muito pequena do total, não falaremos sobre a diferenciação entre as duas finalidades, apenas mencionar que aproximadamente $20 \%$ das operações de investimento e $2 \%$ das de custeio foram prorrogadas no período.

Municípios de todos os territórios apresentaram contratos do AGROAMIGO já no ano de seu lançamento, 2005, mas somente nos últimos meses. Por outro lado, nos dados fornecidos pelo BNB só figuram contratos datados até fevereiro de 2015. Portanto analisamos dados totais do AGROAMIGO no Rio Grande do Norte no período de 2005 a 2014, usamos 
para comparações os anos de 2006 e 2014 - primeiro ano com abrangência mais uniforme nos territórios e último ano completo quanto aos dados, respectivamente.

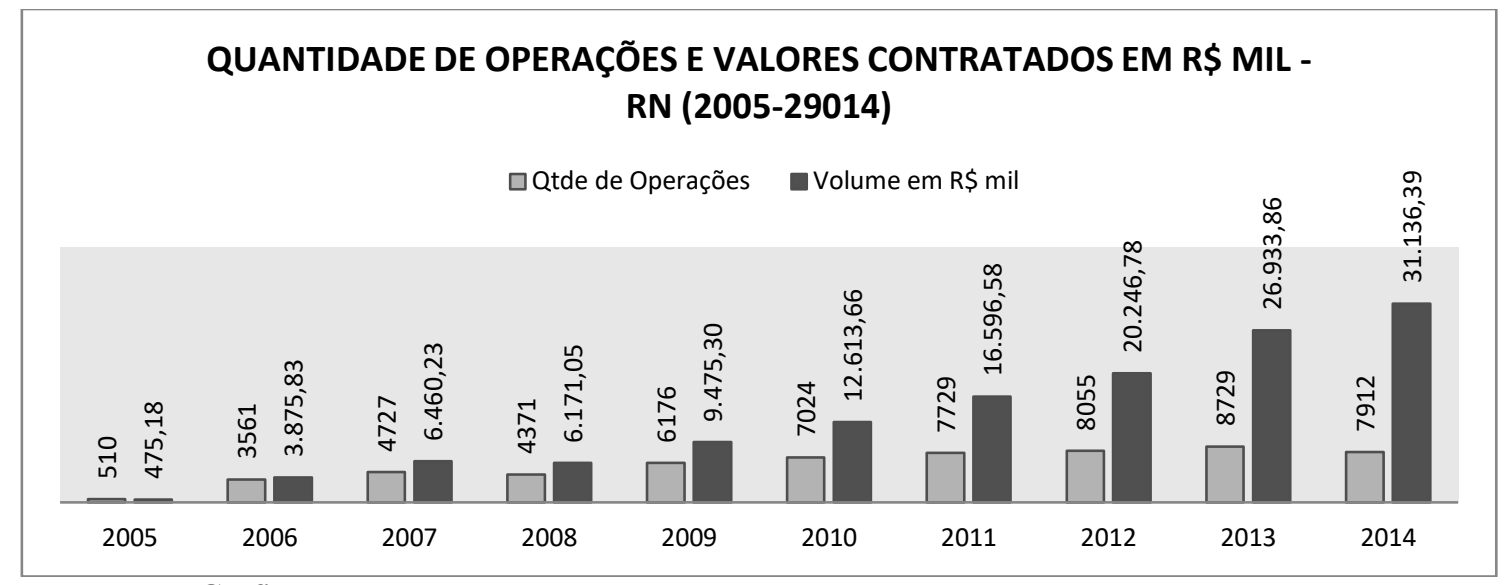

Gráfico 5. Quantidade de Operações e Valores Contratados em R\$ mil de 2005 a 2014 no estado do RN. Fonte: BNB, 2017.

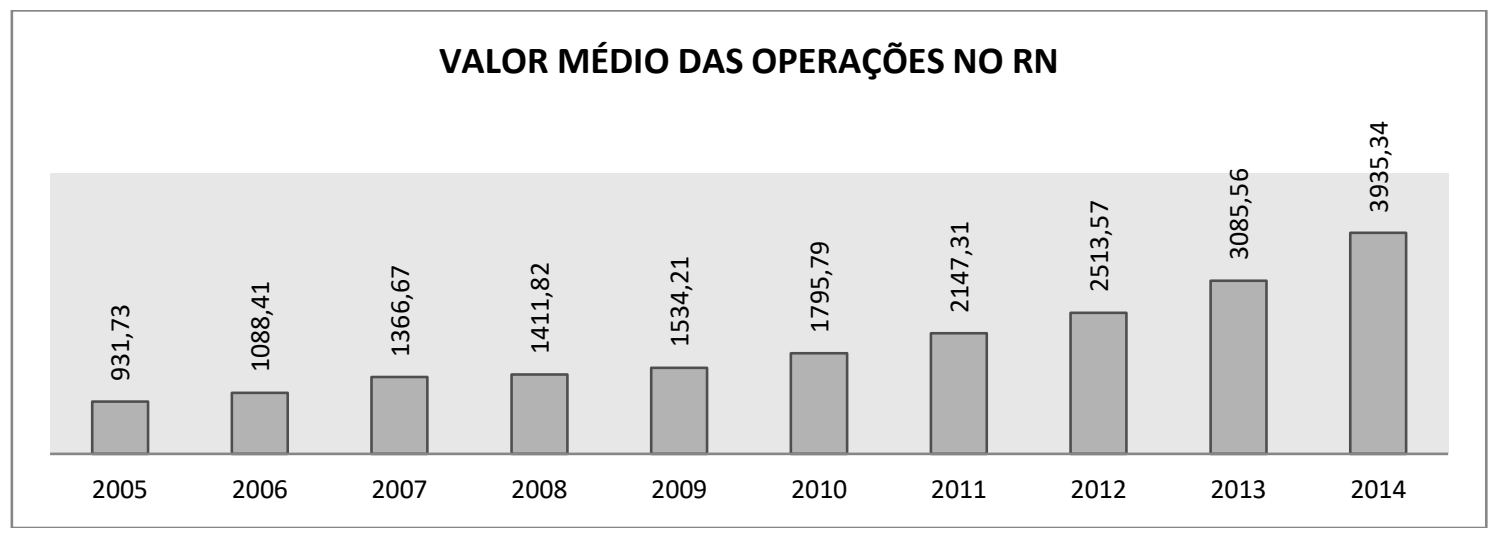

Gráfico 6. Valor médio das operações entre 2005 e 2014 no estado do RN Fonte: BNB, 2017

Os gráficos 5 e 6 mostram a evolução da quantidade, do somatório dos valores liberados e do valor médio das operações do programa AGROAMIGO no Rio Grande do Norte no período analisado. Quando comparamos os dados gerais do AGROAMIGO, gráficos 1 e 2, vemos que no estado o programa apresentou as mesmas quedas no número de contratos identificadas nos dados gerais nos anos de 2008 e 2014, quando comparado com o ano anterior. $O$ valor médio das operações segue uma curva de evolução muito parecida no geral (gráfico 2) e no local (gráfico 6), com as operações no estado apresentado valore médio maior que no geral na maioria dos anos, só perdendo para o geral nos anos de 2005, 2009 e 2010.

Quando comparado município a município ou território a território, o valor médio das operações não apresentou grandes oscilações, então vamos usar o número de operações como proxy do somatório dos valores liberados. Sendo assim, daqui em diante não mais utilizaremos os dados de somatório de valores, somente o número de operações. Tal comportamento do valor médio se dá provavelmente pelo aumento no teto do valor dos contratos, conforme política do administrador do programa.

A evolução da distribuição das operações entre os territórios no estado do Rio Grande do Norte pode ser observada na tabela 2. Esta tabela nos mostra também que um total de 
58.776 operações foram efetivadas no estado entre 2005 e 2014 , totalizando mais de $\mathrm{R} \$$ 133,98 milhões liberados.

\begin{tabular}{|c|c|c|c|c|c|c|c|c|c|c|c|}
\hline \multicolumn{12}{|c|}{ QUANTIDADE DE OPERAÇÕES POR TERRITÓRIO 2005-2014 } \\
\hline & 2005 & 2006 & 2007 & 2008 & 2009 & 2010 & 2011 & 2012 & 2013 & 2014 & $\begin{array}{c}\text { TOTAL } \\
2005-2014\end{array}$ \\
\hline Agreste/Litoral Sul & 63 & 432 & 593 & 782 & 714 & 897 & 975 & 966 & 1050 & 1098 & 7570 \\
\hline Alto Oeste Potiguar & 63 & 408 & 471 & 403 & 789 & 871 & 1152 & 1412 & 1333 & 1179 & 8081 \\
\hline Assú/Mossoró & 57 & 455 & 444 & 234 & 435 & 449 & 519 & 607 & 692 & 595 & 4487 \\
\hline $\begin{array}{c}\text { Sertão Central Cabugí } \\
\text { e Litoral Norte }\end{array}$ & 1 & 60 & 69 & 38 & 140 & 153 & 222 & 143 & 219 & 216 & 1261 \\
\hline Mato Grande & 72 & 220 & 272 & 124 & 249 & 502 & 472 & 482 & 503 & 430 & 3326 \\
\hline Terra dos Potiguaras & 0 & 4 & 95 & 88 & 110 & 198 & 145 & 112 & 113 & 165 & 1030 \\
\hline Potengi & 138 & 373 & 398 & 287 & 399 & 398 & 435 & 437 & 455 & 447 & 3767 \\
\hline Seridó & 2 & 771 & 1235 & 1390 & 1719 & 1680 & 1795 & 1736 & 1996 & 1729 & 14053 \\
\hline Sertão Apodi & 17 & 328 & 519 & 429 & 851 & 943 & 1143 & 1240 & 1321 & 1103 & 7894 \\
\hline Trairí & 88 & 501 & 631 & 596 & 770 & 933 & 871 & 920 & 1046 & 951 & 7307 \\
\hline TOTAL & 501 & 3552 & 4727 & 4371 & 6176 & 7024 & 7729 & 8055 & 8728 & 7913 & 58776 \\
\hline
\end{tabular}

Tabela 2. Evolução do número de operações nos territórios do estado do RN. Fonte dos dados: BNB, 2017. Elaboração dos autores.

O gráfico 7 mostra a participação no acumulado do número de operações por território, percebe-se que apenas os territórios Seridó, Alto Oeste Potiguar e Sertão do Apodi concentraram mais da metade das operações no período.

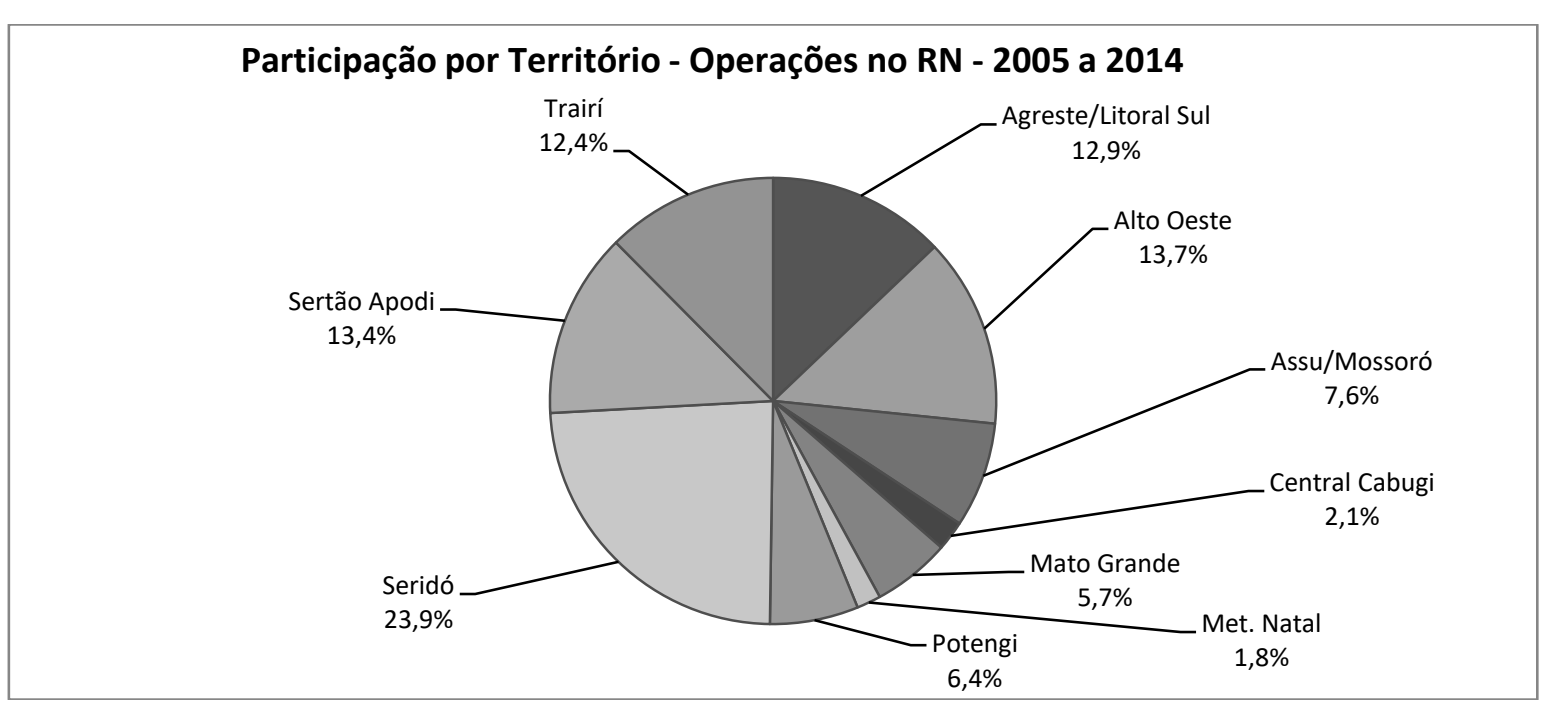

Gráfico 7. Participação por Território no total de operações de 2005 a 2014. Fonte dos dados: BNB, 2017. Elaboração dos autores.

\section{Participação por Gênero: Evolução e nos territórios}

Quanto à participação por gênero, percebe-se que nas operações efetivadas no período no estado do Rio Grande do Norte há uma maior participação nos créditos liberados por parte do sexo masculino do que se verifica nos dados gerais do programa. Enquanto que esta 
participação fica em 52\% no geral, no Rio Grande do Norte quase 55\% das operações foram efetivadas para o sexo masculino.

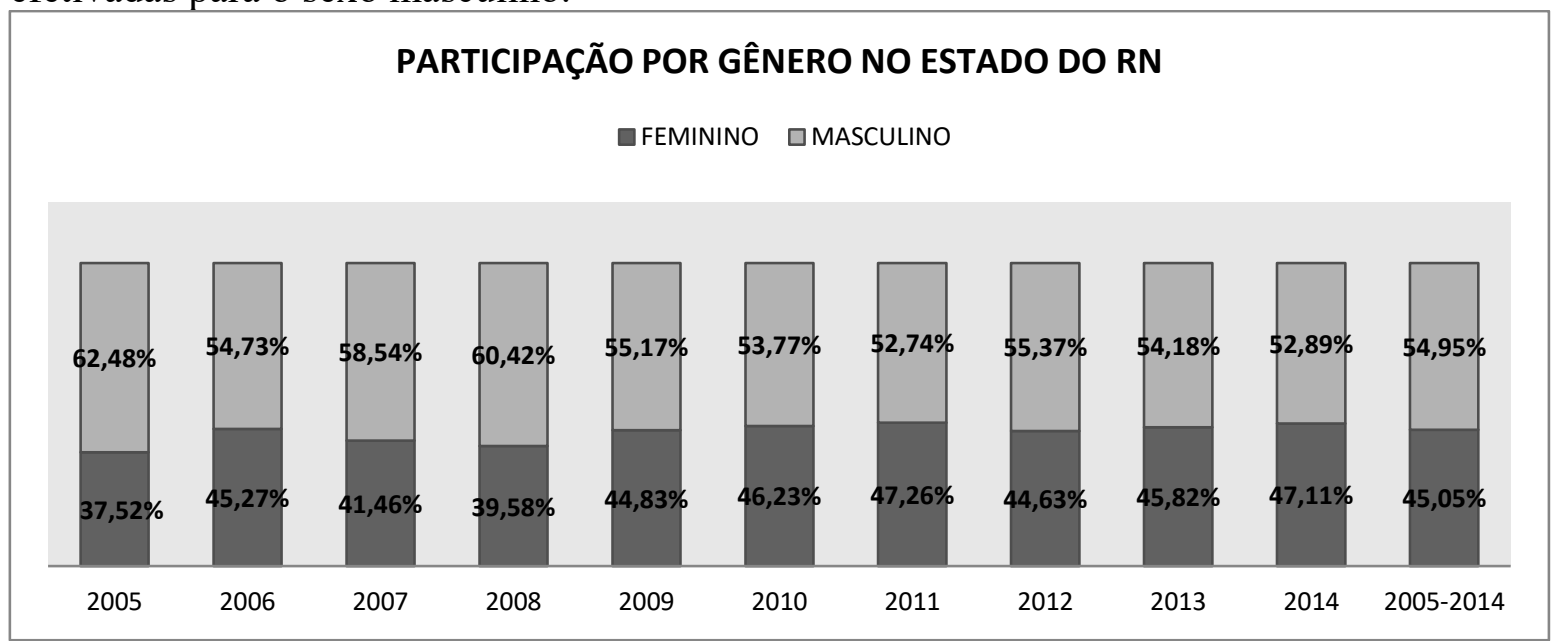

Gráfico 8. Evolução e acumulado da distribuição em gênero. Fonte: BNB, 2017. Elaboração dos autores.

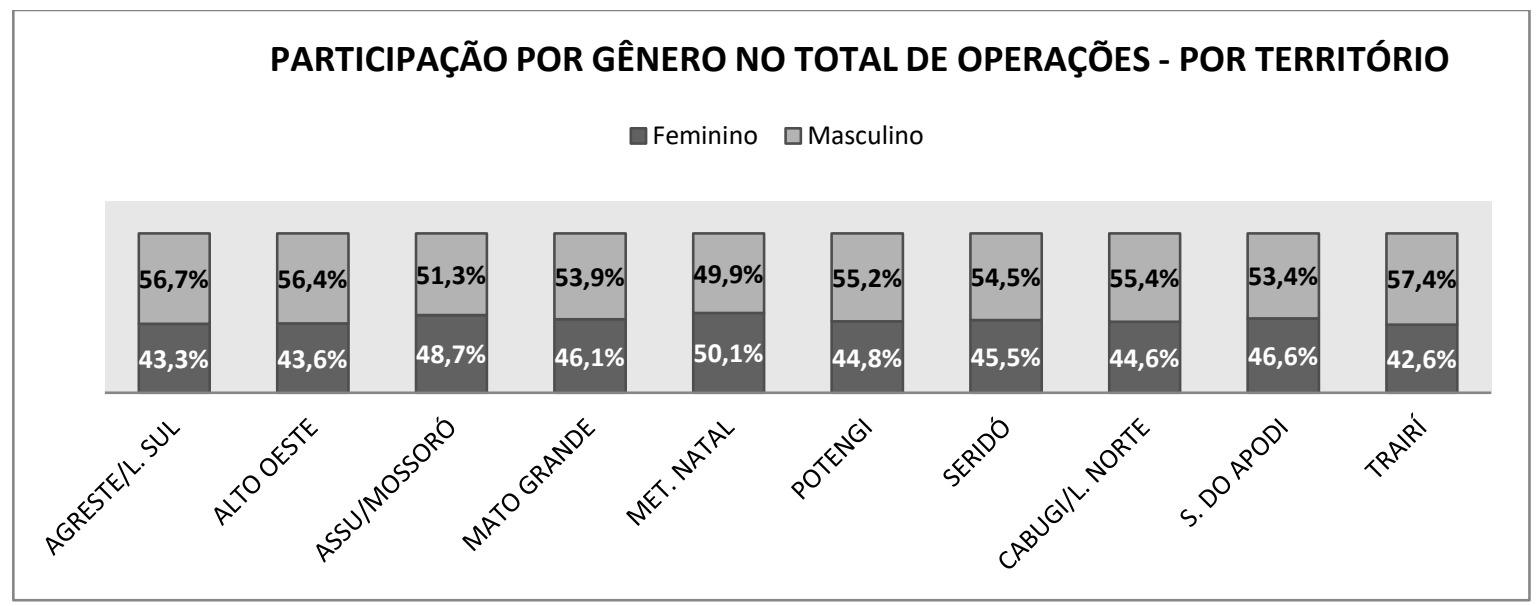

Gráfico 9. Participação por Gênero no total de operações no estado do RN. Fonte dos dados: BNB, 2017. Elaboração dos autores.

Ao acompanharmos a evolução desta participação durante período analisado, percebe-se que em nenhum dos anos a participação feminina foi maior que a masculina e que sua menor participação foi no ano de 2008. Conforme podemos verificar no gráfico 9, a participação feminina no total de contratos no período foi maior do que a masculina em apenas um dos territórios, o da Região Metropolitana de Natal $(50,1 \%)$, não encontramos uma explicação para o fato, mas trata-se da região com maior população urbana do estado. Quando analisado ano a ano, a participação feminina até ultrapassou a masculina em alguns territórios, mas esses números não se sustentaram por mais de dois ou três anos, resultando numa participação menor no somatório do período.

\section{Por ramo de atividade: o domínio da cadeia produtiva da Bovinocultura}

Pelos gráficos 3 e 4 podemos ver que a pecuária obteve um percentual de $80 \%$ dentre os subsetores de atividade, e que à bovinocultura foi reservado $57 \%$ desse percentual de liberações destinado à pecuária. Assim a bovinocultura obteve 45,6\% de todas as operações do AGROAMIGO de 2005 a março de 2017 (dados gerais mais atualizados do programa 
disponibilizados pelo BNB). Quando da análise dos dados do programa apenas no estado do Rio Grande do Norte, esta participação da bovinocultura fica em 59,4 \% das operações.

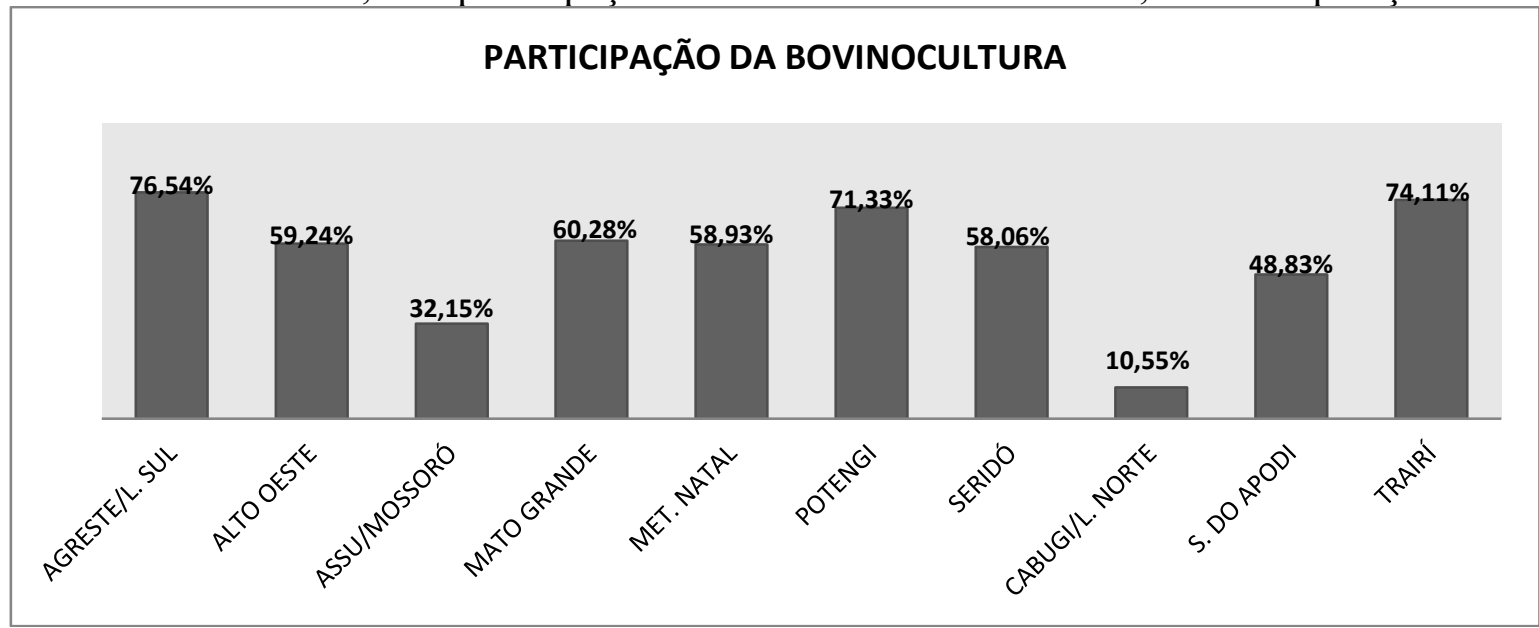

Gráfico 10. Participação da Bovinocultura no total de operações por território no período 2005 a 2014. Fonte dos dados: BNB. Elaboração dos autores.

O gráfico 10 nos mostra nos mostra que no total de operações por território no período a participação da bovinocultura é menor que $50 \%$ apenas em três dos territórios - Sertão Central Cabugi e Litoral Norte, onde quem assume a liderança é caprinocultura com 25,9\% das operações; Assú/Mossoró, onde bovinocultura ainda detém a maior participação com menor intensidade, apresenta boa distribuição entre as atividades, ovinocultura apresenta participação de $13,5 \%$, pesca $10,7 \%$ e todos os produtos da fruticultura somam $3,8 \%$; e Sertão do Apodi, que também tem bovinocultura como o ramo com maior participação, seguido por pecuária diversos com $16,1 \%$, ovinocultura com $15,7 \%$ e caprinocultura com $6,2 \%$, apresentando o maior número dentre os territórios de operações destinadas à apicultura, 137 (1,7\%). A maior concentração no ramo bovinocultura se deu nos territórios Agreste e Litoral Sul, Potengi e Trairí, com participação da bovinocultura no total de operações superior a $70 \%$.

\section{Sobre as prorrogações}

Para analisarmos os números quanto às prorrogações de operações criamos um índice de prorrogação, que é a razão do número de prorrogações pelo total de operações (liberações de crédito) em cada território no período de 2005 a 2014. Sete dos 10 territórios apresentaram valores próximos para este índice, ver gráfico 11.

Os territórios Açu-Mossoró e Sertão Central Cabugi e Litoral Norte apresentaram os maiores índices de prorrogação - 41,46 \% e 50,67\%, respectivamente. Coincidentemente esses territórios foram os que apresentaram menor percentual de operações destinadas à bovinocultura (gráfico 10). O território Alto Oeste apresenta o menor índice de prorrogação, apenas $2,25 \%$. Número muito abaixo dos demais. Não encontramos algum argumento que justificasse tal diferença. Segundo o coordenador regional Evandro Sousa isso pode se dar pelo fato da concentração em bovinocultura naquele território. 


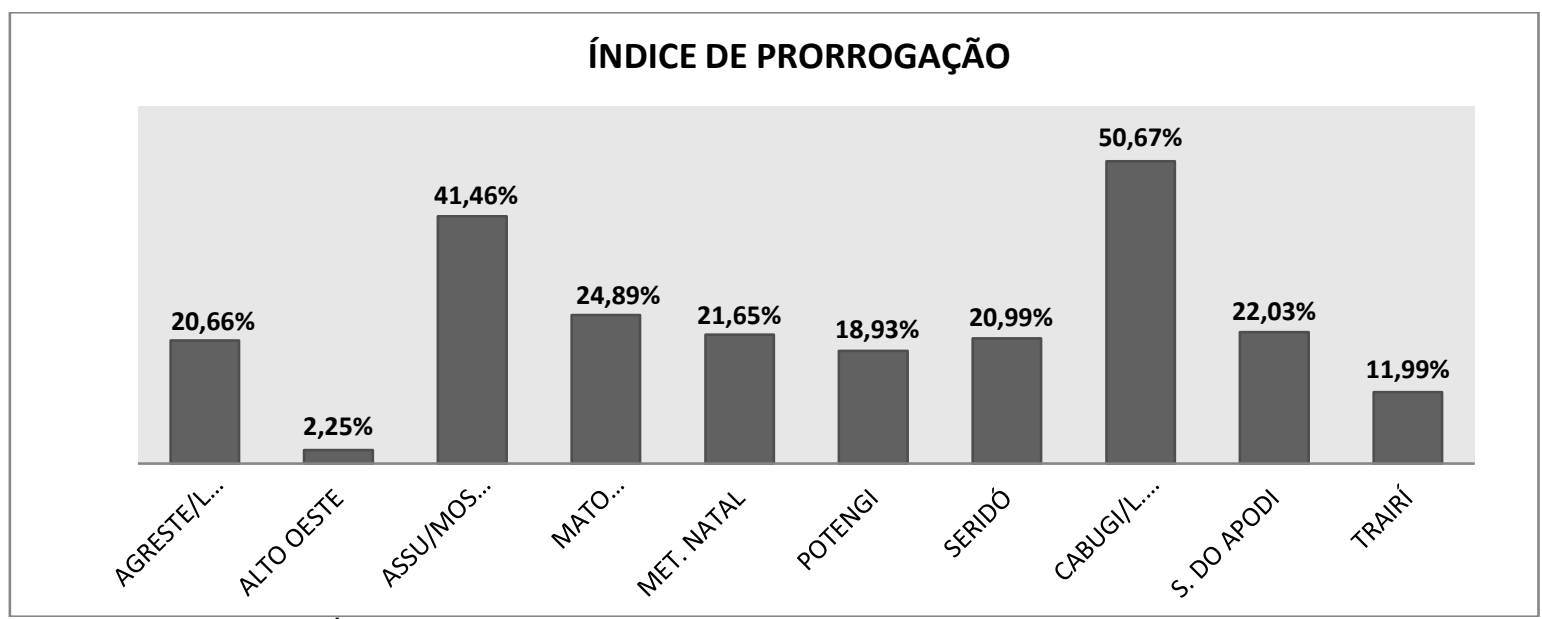

Gráfico 11. Índice de prorrogações por total de operações por território no período 2005 a 2014. Fonte dos dados: BNB, 2017. Elaboração dos autores.

\section{Territórios e número de estabelecimentos rurais}

Comparamos o número de contratos nos anos de 2005, 2006 e 2014 com o número de estabelecimentos rurais em cada município potiguar (segundo Senso Agropecuário de 2006). Analisamos o comportamento desses dados em um único município ou em um território. A figura 2 é um mapa do estado do Rio Grande do Norte colorido de acordo com o número de estabelecimentos rurais de cada município, quanto mais escura a cor do município no mapa maior é o número de estabelecimentos, e vice-versa. De leste para oeste temos uma primeira linha de municípios com maior número de estabelecimentos já no agreste, outra concentração desses municípios na região/território do Seridó, mais uma concentração na junção dos territórios Açu-Mossoró e Sertão do Apodi.

Chamou-nos a atenção a diferença entre os territórios Alto Oeste e Agreste/Litoral Sul. Nestes territórios há concentração de municípios com menor área, mas as semelhanças não se sustentam quando os comparamos em relação ao número de estabelecimentos. Enquanto o primeiro apresentou uma pulverização de cidades com alto e baixo número de estabelecimentos, o segundo apresenta uma concentração de municípios com baixo número no litoral e alto no agreste. Essa porção litorânea do território Agreste/Litoral Sul foi região do estado que apresentou os menores números de estabelecimentos (Baía Formosa, o município com menor número, apresentava em 2006 apenas 13 estabelecimentos).

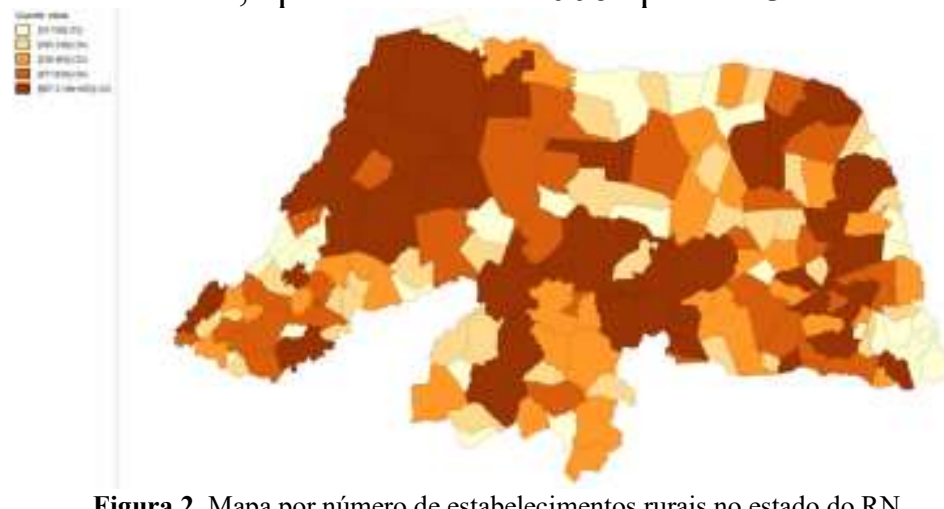

\footnotetext{
Figura 2. Mapa por número de estabelecimentos rurais no estado do RN. Fonte dos dados: IBGE, Senso Agropecuário de 2006. Elaboração dos autores.
} 


\section{Visão através dos gráficos de dispersão}

As figuras 3 e 4 são o gráfico de dispersão da relação entre número de estabelecimentos e número de operações do AGROAMIGO no ano de 2006 (ano que usamos para comparar com 2014, já que em 2005 poucos municípios apresentaram contratações) e o mapa com a seleção dos municípios que apresentaram número de operações maior ou igual a sessenta. Já vemos uma maior dispersão no número de operações, com municípios dos territórios Sertão do Apodi e Seridó já figurando dentre os que realizaram maior número de operações.

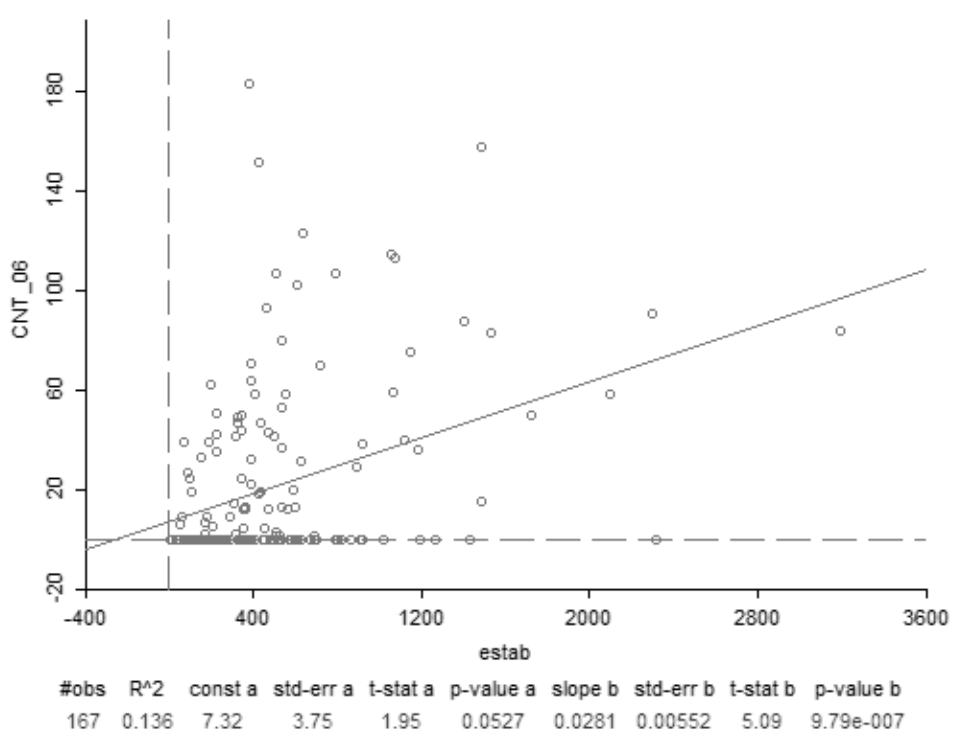

Figura 3. Dispersão da relação entre quantidade de operações em 2006 e número de estabelecimentos rurais nos municípios do RN. Fonte dos dados: BNB, 2017 e IBGE, 2006. Elaboração dos autores.

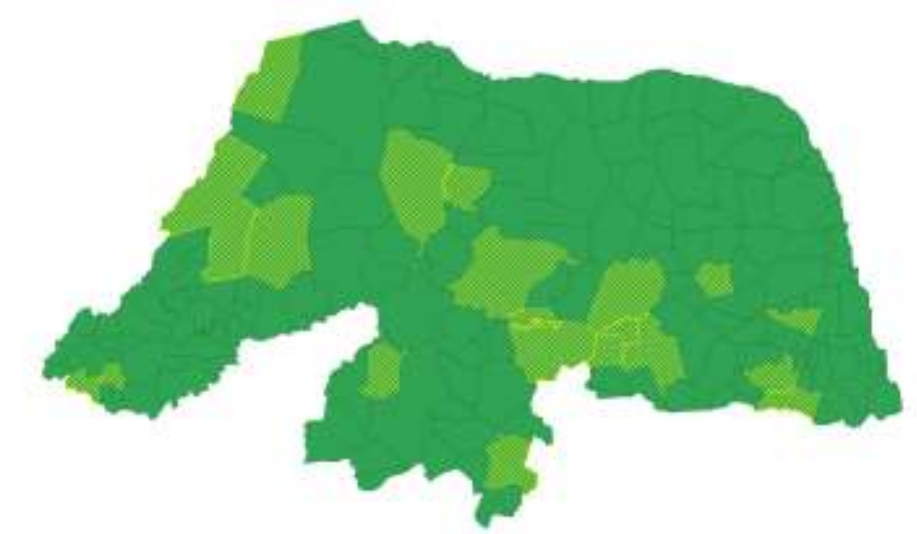

Figura 4. Mapa com seleção dos municípios com maior número de operações no RN em 2006. Fonte dos dados: BNB, 2017. Elaboração dos autores.

As figuras 5 e 6 são o gráfico de dispersão e mapa como os que tivemos para o ano de 2006, mas agora para o ano de 2014 - aqui também, mapa com a seleção dos municípios com número de operações maior ou igual a 60. Comparando estes com os anteriores percebemos que o com o passar dos anos o grupo dos municípios com maior número de operações passou a conter municípios de todos os territórios. Na figura 5 a inclinação da reta (coeficiente de correlação) nos mostra que correlação entre as variáveis se tornou maior com 
o passar dos anos. Isso demonstra que a vinculação entre o número de estabelecimentos rurais e o de operações ficou mais forte. Percebemos que nenhum município do litoral figura como grande tomador.

No território Agreste e Litoral Sul a diferença nos números estabelecimentos é seguida e mantida no quesito número de operações. Assim como no território Alto Oeste Potiguar, que a pulverização entre os municípios com maior número de estabelecimentos também se manteve na quantidade de operações.

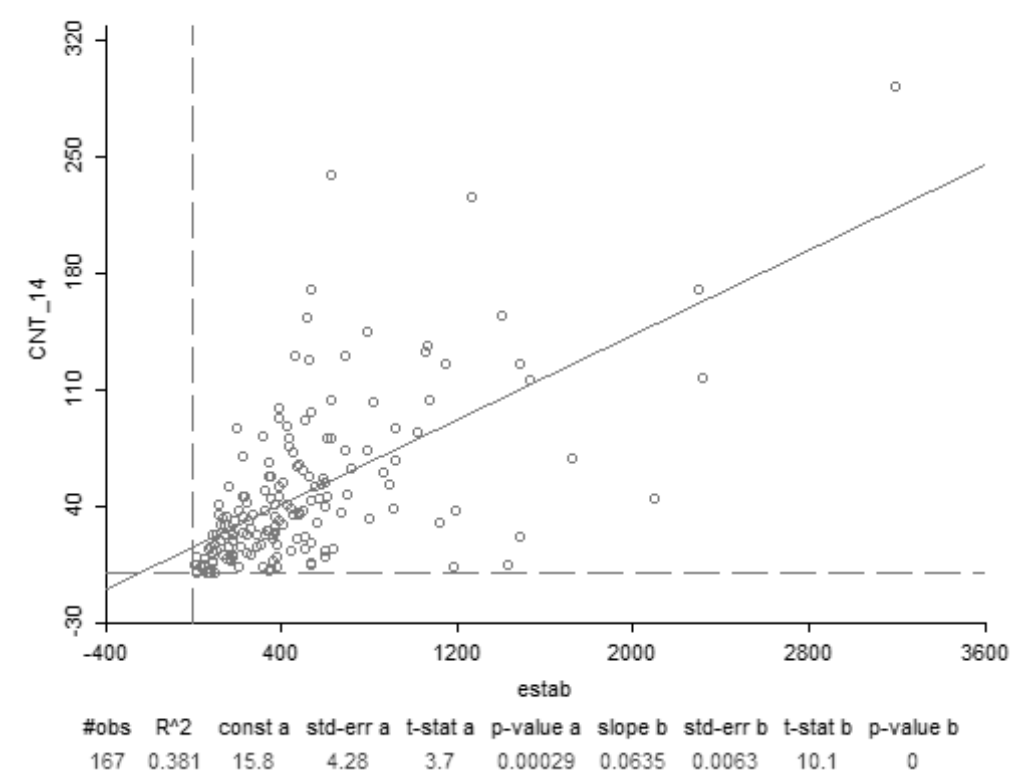

Figura 5. Dispersão da relação entre quantidade de operações em 2014 e número de estabelecimentos rurais nos municípios do RN. Fonte: BNB, 2017 e IBGE, 2006. Elaboração dos autores.

No território Seridó percebemos a inclusão dos municípios do Oeste no grupo dos que figuram como maiores tomadores. Assim como nos territórios Sertão do Apodi, Açu/Mossoró, Potengi e Trairí, que mais municípios foram incluídos nesse grupo.

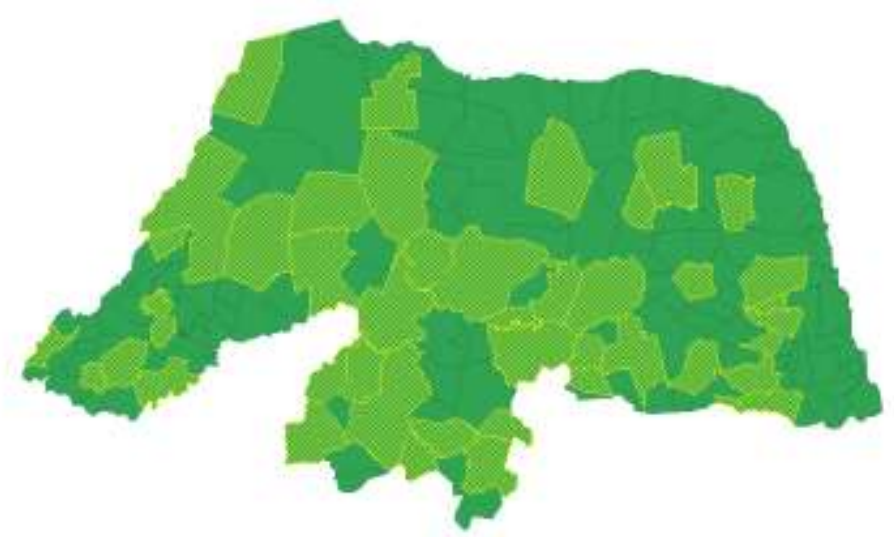

Figura 6. Mapa com seleção dos municípios com maior número de operações no RN em 2014. Fonte: BNB, 2017. Elaboração dos autores.

Os territórios de Mato Grande e Terra dos Potiguaras também tiveram municípios incluídos no grupo de maiores tomadores, fato que ainda não ocorria em 2006. O território Sertão Central Cabugi e Litoral Norte teve um único representante no grupo de maiores 
tomadores nos anos analisados mesmo antes da suspensão das atividades do programa no território.

\section{CONSIDERAÇÕES FINAIS}

O período analisado foi de grande crescimento econômico e melhora dos índices sociais no país, principalmente na região Nordeste. Certamente, onde esses índices sociais mais melhoraram foi na região conhecida anteriormente como bolsão de pobreza, localizada no semiárido nordestino. Sabemos que outras políticas públicas foram desenvolvidas no país e na região no período, na maioria delas políticas que visavam a manter o sertanejo em suas terras ou seu lugar, mantendo uma renda básica para seu sustento e melhores condições de infraestrutura. São exemplos o Bolsa Família, o aumento real do salário mínimo, o Luz para Todos etc. No âmbito da agricultura familiar podemos citar os aumentos consideráveis nos valores do Plano Safra destinados ao Pronaf. Este, sabemos que não chegaria, ou chegaria com intensidade menor que a necessária, ao produtor rural de menor renda se não existisse o AGROAMIGO.

Nossos resultados nos mostraram que a concentração do AGROAMIGO no estado do Rio Grande do Norte não só se deu nos municípios de maior número de estabelecimentos agrícolas - onde há menor concentração de terras - como também na região do semiárido potiguar. O programa que se diferencia das demais políticas públicas pelo carácter não paternalista, já que não garante a renda e sim o crédito, também se caracterizou pela melhor aderência na região do estado onde as pessoas mais sofrem com secas. A maneira como se deu a evolução do AGROAMIGO no Rio Grande do Norte nos mostrou que ele é um programa que busca diminuir distâncias sociais não só locais, mas também entre o semiárido e a região menos atingida pelas secas. O AGROAMIGO se tornou um ativo para que agricultores familiares aproveitem oportunidades que vieram graças a outras políticas.

Não podemos afirmar baseado em nossos resultados, que a ação do AGROAMIGO na economia do Rio Grande do Norte já cause efeitos secundários como na hipótese de causação circular, mas podemos afirmar que o programa se trata de um ativo de grande importância para o acesso à estrutura de oportunidades necessária ao pequeno agricultor familiar das regiões onde predomina a agricultura familiar e a seca no estado. A bancarização e o acesso ao crédito que antes não faziam parte do cotidiano desse agricultor, hoje já realidade para uma parcela do público alvo do programa.

\section{REFERÊNCIAS}

ABRAMOVAY, R.; RODRIGUES JR, M.; MADEIRA, G. de A., GONÇALVES, M.F.; MACIEL, I. S. R.; SANTOS, R. A. dos. Cinco anos de agroamigo: retrato do público e efetivo programa. Fortaleza: Banco do Nordeste do Brasil, 2012.

CROCCO, M. A.; SANTOS, F.; FIGUEIREDO, A. Exclusão financeira no Brasil: uma análise regional exploratória. Rev. Econ. Polit., [s.1.], v. 33, n. 3, p.505-526, 2013.

FREITAS, A. F. Organizações de microfinanças: inovações e desafios para a inclusão financeira. Revista de Administração da Ufsm, [s.1.], v. 6, n. 1, p.39-54, 12 abr. 2013. Universidad Federal de Santa Maria. http://dx.doi.org/10.5902/198346593826. 
KAZTMAN, R.; FILGUEIRA, C. (1999). Marco conceptual sobre activos, vulnerabilidad y estructura de oportunidades. Montevidéu: Cepal.

LEITE, S. P.; WESZ JÚNIOR, V. J. Um estudo sobre o financiamento da política de desenvolvimento territorial no meio rural brasileiro. Revista de Economia e Sociologia Rural, Piracicaba - Sp, v. 50, n. 4, p.645-666, dez. 2012. FapUNIFESP (SciELO). http://dx.doi.org/10.1590/s0103-20032012000400004.

NUNES, E. M.; SILVA, P. S. G.; SILVA, M. R. F.; SÁ, V. C. (2020). O Índice de Condições de Vida (ICV) em Territórios Rurais do Nordeste: evidências para os territórios Açu-Mossoró e Sertão do Apodi, no Rio Grande do Norte. Revista de Economia e Sociologia Rural [IMPRESSO], 58(1), e190917. https://doi.org/10.1590/1806-9479.2020.190917

NUNES, E. M.; SCHNEIDER, S; MATOS-FILHO, J; GODEIRO-NUNES, K. F.; AQUINO, J. R. de. Políticas Agrárias e Agrícolas no Contexto do Desenvolvimento do Nordeste: evolução, desafios e perspectivas. Planejamento e Politicas Publicas (IPEA), v. 43, p. 91-126, 2014.

NUNES, E. M.; ARAUJO, I. J.; FRANÇA, A. R. M.; LIMA, J. S. S. de; MEDEIROS, L. S. Microcrédito, Infraestrutura e Desenvolvimento Rural: o AGROAMIGO Investimento e Custeio na agricultura familiar de territórios do Rio Grande do Norte. Revista Econômica do Nordeste, v. 46, p. 53-69, $2015 \mathrm{a}$.

NUNES, E. M.; FRANÇA, A. R. M.; LIMA, J. S. S. de; MEDEIROS, L. S. Novidades (Novelty) na Agricultura Familiar e sua associação com a agroecologia na produção de hortifrutigranjeiros no Território Sertão do Apodi (RN). REDES (Santa Cruz do Sul. ONLINE), v. 23, p. 213-236, 2018.

NUNES, E. M.; SILVA, P. S. G.; SIlvA, M. R. F.; SÁ, V. C. (2015). Dinamização Econômica e Agricultura Familiar: limites e desafios do apoio a Projetos de Infraestrutura (Proinf) em territórios rurais do Nordeste. Revista de Economia e Sociologia Rural, Piracicaba - Sp, v. 53, n. 3, p.529-554, set. 2015b. FapUNIFESP (SciELO). http://dx.doi.org/10.1590/1234-56781806-9479005303009.

SANTOS, Carlos A. Análise de impactos socioeconômicos do microcrédito: dificuldades metodológicas e analíticas. Revista de Administração Pública, [s.1.], v. 41, n. 1, p.147-160, 2007.

SCHUMPETER, Joseph Alois. A teoria do desenvolvimento econômico: uma investigação sobre lucros, capita, credito, juro e o ciclo econômico. 3. ed. São Paulo: Nova Cultural, 1988.

SILVA, Guilherme Jonas Costa da; JAYME-JR., Frederico G.. Estratégia de localização bancária: teoria e evidência empírica aplicada ao Estado de Minas Gerais. Econ. Soc., [s.1.], v. 22, n. 3, p.729-764, dez. 2013.

SOARES, Ricardo Brito; BARRETO, Flávio Ataliba; AZEVEDO, Marcelo Teixeira. Condicionantes da saída da pobreza com microcrédito: o caso dos clientes do Crediamigo. Estud. Econ.[online]. 2011, vol.41, n.1, pp. 119-142. 